\title{
The evaluation of cities for environmentally sustainable transport based on DEA method
}

\author{
JIANG Jian \\ School of Traffic and Transportation, Beijing Jiaotong University, Beijing 100044, China \\ Email: jjiang@bjtu.edu.cn
}

\begin{abstract}
Keywords: sustainability; transportation; DEA; effect evaluation
Abstract. Transportation management is essential for the region planning and governance. Transport planning plays an important role in designing the city plan. The strategy of transportation of sustainability is also indispensable for the construction of eco-cities. This paper mainly focuses on evaluation of the improvement by introducing the environmentally sustainable transportation policies in Japan. By the introduction of DEA method, the evaluation of sustainability among the regions is done and we can find out the EST cities are indeed with high sustainable level on transport.
\end{abstract}

\section{Introduction}

Sustainable development is a very important topic around the world in recent decades. The core idea is to meet the human being's needs as well as preserving the resources and environment of the world, so that the needs of human can be met not only at the time being, but also in the future for the next generations. Sustainable is the systematically combination of environment, economic and social. Based on this consideration, we have to make more consideration on the city planning and construction.

Japan confronted a boom of economic development after the World War II, and is becoming one of the most advanced countries all over the world. However, the consumption of energy in Japan is growing up steadily, which most of the energy consumed is non-renewable resources such as coals and oil. It is not considered sustainable for the ratio to consume so much non-renewable resources especially after the experience of the oil crisis. And now, the accident of the Fukushima Daiichi Nuclear Plant makes the public uneasy for the safety of nuclear power particularly for the places where suffers from natural disasters easily. Other means of clean energy is restricted by the nature conditions crucially and the cost remains high. Therefore, it is more important to control the amount of energy consumption.

The share of energy consumption which the transport sector occupied is about $20 \%$ and is growing up gradually. In 2014, the ratio has reached $23.1 \%$, near to a quarter of the total in Japan. We can draw some impression from the figure that the energy consumption in transport sector is increasing successfully although Japan itself is a country that is lack of energy. Regarding this, Japan has done much effort on the improvement on contributing sustainable society. Now, Japan has already built up the system of constructing Environmentally Sustainable Transport in some model cities and prefectures. Various kinds of policies are proposed to make the transportation smoothly in order to consume less energy and emit less greenhouse gases. This paper utilizes the case of the model of Environmentally Sustainable Transport places to do analysis on the evaluation.

\section{Methodology}

Data Envelopment Analysis (DEA for short) is considered to be a useful operational research tool and becoming more and more popular on the field of evaluation analysis. It is a linear programming methodology to measure the efficiency of multiple decision-making units when the production process presents a structure of multiple inputs and outputs. It is proposed by Charnes, Cooper \& Rhodes at first and developed into some other models with the years went by and is basically used to empirically measure productive efficiency of decision making units. Now it is spread and used widely in many fields 
for efficiency evaluation and it can be also adopted for the evaluation of the efficiency by environmentally sustainable transportation policies [1].

DEA method focuses on the evaluation given some input variables and output variables. There is no need to set weight on each variable but only consider the mathematical relationships of the variables. It can be used for both production and cost data. It is also useful because it takes into consideration returns to scale in calculating efficiency, allowing for the concept of increasing or decreasing efficiency based on size and output levels. A drawback of this technique is that model specification and inclusion/exclusion of variables can affect the results [2].

The output of the analysis should be the index of sustainability in transport sector. The energy consumption is no doubt in the index and it is easy to calculate, besides, the emission of greenhouse gas also affects the degree of sustainability, but the estimation of the emission remains to be a problem. The speculation of the emission mainly based on the transportation survey, but the concrete amount by cities and prefectures cannot be inferred concisely. Furthermore, the energy consumption is accompanied with greenhouse emission. So we decide to use the energy consumption as the only output variable in the analysis. By the way, BCC model expects the amount of the output the more the better, but in the case of this paper, less energy consumption is apparently expected. Consequently, we do the treatment to reverse the amount of the output oppositely so that it can match the methodology.

The input of the analysis should be the fundamental parameters of the region. For the availability of the data, we review the yearbook of transport in Japan and decide to choose the intensity of population, the number of cars, the length of road, and the area of roads as input factors of this analysis. All the data is available by the investigation of road survey in Japan.

\section{Data and analysis result}

Environmentally Sustainable Transport is a new policy vision which was proposed by the Organization for Economic Co-operation and Development and its commitment is to plan and implement policy on transport and environment based on a long-term perspective. By presenting the specific vision for future transportation, it is expected to increase awareness and choose transport activities and lifestyles with reduced environmental loads. The regions are selected by Japan's government as Environmentally Sustainable Transport model by three times from the year 2004, 2005 and 2006 across almost all the country. The model regions are not only cities, but also prefectures, and mainly focused in the Kansai region and Kanto region. For the consistency of analysis, we start with the prefectures which are selected as EST model regions and contains EST model cities. First, we analysis the efficiency by regions like Kansai, Kanto, Kyushu, Tyugoku, Tohoku and so on to find the relatively efficiency of places in almost the same geographic situations. The DEA analysis software we used is the College Analysis Version 4.0 developed by Fukuyama Heisei University. We select the data of the year 2014 [3-7] and the result is as follows:

Table 1 Analysis result of Kansai Area

\begin{tabular}{|c|c|}
\hline Prefecture in Kansai Area & Efficiency: \\
\hline Shiga & 0.731 \\
\hline Kyoto & 1.000 \\
\hline Osaka & 1.000 \\
\hline Hyogo & 1.000 \\
\hline Nara & 0.813 \\
\hline Wakayama & 0.798 \\
\hline
\end{tabular}


Table 2 Analysis result of Kanto Area

\begin{tabular}{|c|c|}
\hline Prefecture in Kanto Area & Efficiency: \\
\hline Ibaraki & 0.943 \\
\hline Tochigi & 1.000 \\
\hline Gunma & 1.000 \\
\hline Saitama & 1.000 \\
\hline Chiba & 1.000 \\
\hline Tokyo & 1.000 \\
\hline Kanagawa & 0.944 \\
\hline
\end{tabular}

Table 3 Analysis result of Kyushu Area

\begin{tabular}{|c|c|}
\hline Prefecture in Kyushu Area & Efficiency: \\
\hline Fukuoka & 1.000 \\
\hline Saga & 0.828 \\
\hline Nagasaki & 0.970 \\
\hline Kumamoto & 0.992 \\
\hline Oita & 0.940 \\
\hline Miyazaki & 0.897 \\
\hline Kagoshima & 1.000 \\
\hline
\end{tabular}

Table 4 Analysis result of Tohoku Area

\begin{tabular}{|c|c|}
\hline Prefecture in Tohoku Area & Efficiency: \\
\hline Aomori & 0.999 \\
\hline Iwate & 1.000 \\
\hline Miyagi & 1.000 \\
\hline Akita & 0.958 \\
\hline Yamagata & 0.873 \\
\hline Fukushima & 1.000 \\
\hline
\end{tabular}

For the conclusion of this result of analysis, it is found that in all the areas, the efficiencies of sustainability environmental transportation are not obviously separated. Good balance is taken among the prefectures in the geographic regions. Among all the areas analyzed, the Kanto Area is the most balanced area, while in Kansai, the efficiency differs a little much from center area to outside area. In Kyushu, Fukuoka and Kagoshima are the energy-consuming high efficiency prefectures while Shiga and Miyazaki are the prefectures more environmental. While in Tohoku, Yamagata is considered to be the environmental prefecture.

After that, we analysis the EST efficiency of the prefectures which are selected as an EST model region: Ishikawa, Kanagawa, Kyoto, Hyogo, Nara, Mie. 
Table 5 Analysis result of EST model areas

\begin{tabular}{|c|c|}
\hline Prefecture as EST model area & Efficiency: \\
\hline Ishikawa & 0.771 \\
\hline Kanagawa & 1.000 \\
\hline Kyoto & 1.000 \\
\hline Hyogo & 1.000 \\
\hline Nara & 0.817 \\
\hline Mie & 0.669 \\
\hline
\end{tabular}

The efficiencies of the six prefectures selected as EST model regions differ seriously. Obviously that advanced place with more population and traffic consumes more energy and low efficiency compares with less developed place. It demonstrates that city planning for EST is more important than that in the countryside, and further research for making corresponding policies should be done more on the city planning in detail.

By the way, as it is very crucial for big cities to do proper city planning for EST, we also do analysis for the six main prefectures with high population density and the result is as follows.

Table 6 Analysis result of High population density areas

\begin{tabular}{|c|c|}
\hline Prefecture as EST model area & Efficiency: \\
\hline Tokyo & 1.000 \\
\hline Kanagawa & 0.952 \\
\hline Osaka & 0.851 \\
\hline Hyogo & 1.000 \\
\hline Aichi & 1.000 \\
\hline Fukuoka & 0.904 \\
\hline
\end{tabular}

The result may be out of imagination that Osaka is the best prefecture for EST although the amount of population and traffic is very large. There are many EST model districts in Osaka which maybe the reason for the result. Tokyo which is regarded as a cosmopolitan should do more on the energy resuming and do effort on the sustainable of the country as to the world.

\section{Acknowledgements}

This work was financially supported by Project of science and technology research and development program of China Railway Corporation (2014X009-B).

\section{References}

[1] Charnes A., Cooper W. W. etc.,Data Envelopment Analysis Theory, Methodology and Applications, Kluwer Acadamic Publishers, 1995.

[2] Yoshino D., Fujiwara A.Potential Reduction of CO2 Emissions in Transport Sector and Its Countermeasures Based on DEA, Proceedings of Infrastructure Planning Vol.41 CD-ROM,2010.

[3] Ministry of Infrastructure and Transport in Japan. The Yearbook of Car Transportation Statistics. [4] Agency for Natural Resources and Energy, Ministry of Economy, Trade and Industry of Japan. The Statistics Data of Transportation. 
[5] The Statistics Bureau of Japan, the Ministry of Internal Affairs and Communications of Japan. Population census of Japan.

[6] Information on http://en.wikipedia.org/wiki/Data_envelopment_analysis

[7] Information on http://www.env.go.jp/en/air/est/index.html 